\title{
Материалы теплоизоляционного назначения из минерального сырья и техногенных отходов
}

\author{
Манакова Н.К., Суворова О.В.
}

Институт химии и технологии редких элементов и минерального сырья им. И.В. Тананаева ФИЦ КНЦPAH, Anamumbl,n.manakova@ksc.ru,ov.suvorova@ksc.ru

Аннотация. Обоснована возможность получения высококачественных блочных вспененных материалов на основе кремнеземсодержащих техногенных отходов по низкотемпературной технологии. Исследованы способы улучшения эксплуатационных свойств пеносиликатов путем введения модифицирующих добавок и использования различных технологических приемов. Экспериментально установлены оптимальные составы и технические условия получения вспененных материалов, отвечающих нормативным требованиям, предъявляемым к материалам и изделиям строительным теплоизоляционным, что позволяет рекомендовать их для утепления промышленных и гражданских зданий и сооружений.

Ключевые слова: техногенные отходы, минеральное сырье, модифицирующие добавки, пеностекла, пеносиликаты, блочные вспененные материалы.

\section{Heat-insulating materials from mineral raw materials and industrial wastes}

\section{Manakova N.K., Suvorova O.V.}

Tananaev Institute of Chemistry and Technology of the Federal Research Centre Kola Science Centre of the Russian Academy of Sciences, Apatity,e-mail:n.manakova@ksc.ru,ov.suvorova@ksc.ru

\footnotetext{
Abstract. The possibility of obtaining high-quality block foam materials based on silica-containing industrial wastes using low-temperature technology is substantiated. Methods for improving the operational properties of foam silicates by introducing modifying additives and using various technological methods have been investigated. Experimentally, we selected the optimal compositions and technical conditions for the production of foamed materials that meet the regulatory requirements for materials and products for building insulation. That allows us to recommend them as heat insulators in the construction and reconstruction of industrial and civil buildings.

Key words: industrial waste, mineral raw materials, modifying additives, foam glass, foam silicates, block foam materials.

В настоящее время вопрос переориентации строительной отрасли в сторону неорганических утеплителей является одним из приоритетных. Уникальным теплоизоляционным материалом является пеностекло, которое можно использовать в любых климатических условиях на различных строительных объектах. Пеностекло выпускается несколькими производителями небольшими партиями на производствах невысоких мощностей. Наработан значительный опыт производства и применения этого материала. Тем не менее, пеностекло не стало материалом, применяемым повсеместно, что связано как со сложностями технологии, так и с его высокой себестоимостью. Пеностекольный материал имеет перспективы выхода на строительный рынок не столько за счет снижения себестоимости и рыночной цены, сколько за счет придания ему дополнительных потребительских свойств. Улучшение технических характеристик для более широкого использования таких вспененных материалов в различных отраслях народного хозяйства требует дополнительных исследовательских подходов и технологических решений.

Классическая порошковая технология, разработанная в 30-х годах академиком И.И. Китайгородским, обусловлена высокими производственными затратами, которые связаны, в первую очередь, с использованием специально сваренного стекла, и переставшей отвечать современным требованиям схемой производства, что обеспечивает рыночную неконкурентоспособность пеностекла (Терещенко И.М., 2017, Кетов А.А., 2007, Кетов А.А., 2015).
} 


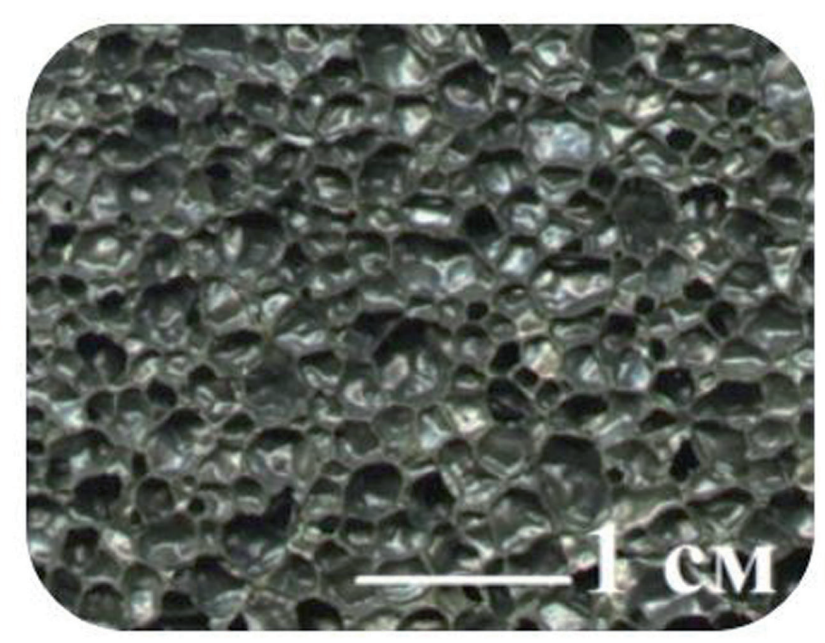

a

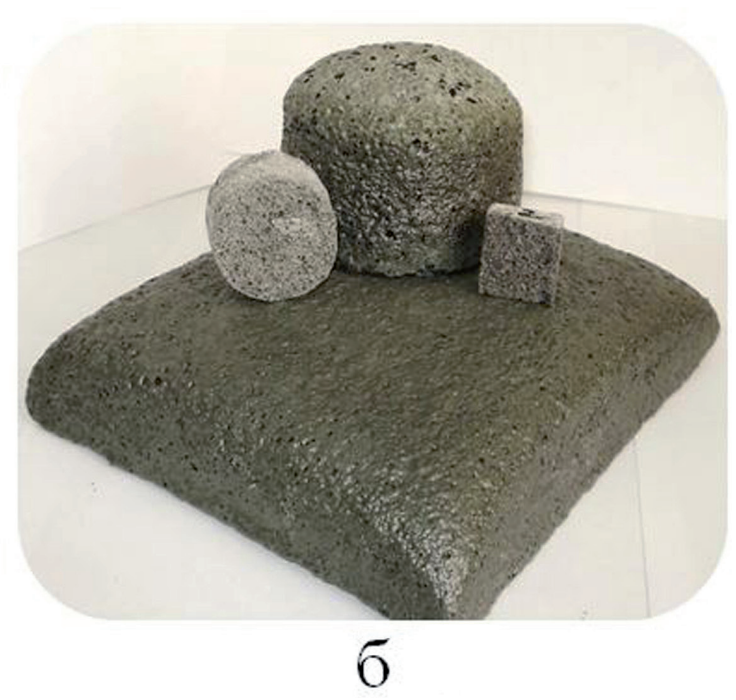

б

Рис. 1. Структура (а) и внешний вид (б) пеностекольного материала.

Fig. 1. The structure (a) and appearance (b) of foam glass.

Отчасти снижение себестоимости пеностекла возможно при использовании отходов бытового стекла и боя стекольного производства. Главенствующим направлением исследований в области теплоизоляционных материалов является разработка технологий получения материалов на основе отходов промышленности. Такое сырье позволяет снизить себестоимость продукции, а также сохранить запас природных ресурсов (Пат. РФ № 2267468, 2006, Кудяков А.И. и др., 2002, Манакова Н.К. и др., 2019, Суворова О.В. и др., 2019, Тихомирова И.Н. и др., 2008).

В Отделе технологии силикатных материалов ИХТРЭМС КНЦ РАН в течение многих лет проводятся исследования по получению высококачественных строительных материалов, в том числе эффективных теплоизоляционных материалов, с использованием местного минерального и техногенного сырья.

С привлечением стеклоотходов и хвостов обогащения апатито-нефелиновых руд был разработан способ получения пеностекла, которое можно рекомендовать использовать как теплоизоляционный облицовочный материал при строительстве и реконструкции сооружений различного типа (Пат. РФ №2246457, 2005). На рисунке 1 приведены макроструктура и фотография разработанного пеностекла.

В основу его разработки входил анализ диаграммы плавкости системы кварц $\left(\mathrm{SiO}_{2}\right)$ - альбит $\left(\mathrm{NaAlSi}_{3} \mathrm{O}_{8}\right)$ - пентаоксодисиликат натрия $\left(\mathrm{Na}_{2} \mathrm{Si}_{2} \mathrm{O}_{5}\right)$, который позволил определить оптимальные составы и температуры вспенивания шихты. Для получения пеностекла использовался состав, мас. \%: стеклоотходы 58.5-64.5, апатит-нефелиновые хвосты 15.0-22.6, кварц 15.5-17.2, газообразователь (мел, сажа или графит) 3.3-4.0, который подбирался таким путем, чтобы при температуpax, не превышающих $900^{\circ} \mathrm{C}$, происходило полное плавление шихты, а вязкость силикатного расплава была достаточно высокой и газовые пузырьки при этом не укрупнялись с последующим прорывом газовой фазы. Все компоненты сырьевой смеси представляли собой техногенные отходы (Пат. РФ №2246457, 2005, Лащук В.В., 2007). В разработанном материале использовалась наиболее экологически опасная часть отвальных продуктов горнопромышленного комплекса - наиболее тонкодисперсная.

Технические характеристики пеностекольного материала: плотность 200-400 кг/м ${ }^{3}$, прочность при сжатии 1.3-1.9 МПа, водопоглощение 1.75-2.95 \%, коэффициент теплопроводности 0.07-0.13 Вт/м $\cdot$ К, морозостойкость - не менее 50 циклов.

Поверхность изделий из пеностекла может быть гладкой или имитирующей натуральные каменные материалы. Поверхность материала, который не подвергался дополнительной обработке, 
имеет серо-зеленую окраску, но она так же может быть покрыта цветной глазурью без ухудшения эксплуатационных характеристик.

Предлагаемый материал имеет относительно высокую прочность и долговечность, обладает высокой огнестойкостью, не подвержен воздействию плесени и вредителей. В отличие от легких (на пористых заполнителях) и ячеистых бетонов характеризуется меньшим показателем водопоглощения. Это обеспечивает стабильность коэффициента теплопроводности в сухих и во влажных условиях эксплуатации.

При переработке апатито-нефелиновых и эвдиалитовых руд месторождений Мурманской области возможно образование значительного количества побочных кремнеземсодержащих продуктов. В связи с этим возникает вопрос их утилизации с получением полезных материалов, в частности строительных. Использование кремнеземсодержащих отходов при получении теплоизоляционных строительных материалов является актуальным на сегодняшний день направлением и открывает обширную область научных исследований. Вместе с тем, известно, что микрокремнезем может использоваться для создания пеносиликатов за счет образования вяжущих композиций со щелочами. Источником порообразующих газов в области пиропластичного состояния в данном случае являются гидратированные полисиликаты натрия, которые образуются при добавлении раствора гидроксида натрия к высокоактивному аморфному кремнезему (Казанцева Л.К. и др., 2012, Пат. РФ № 2300506, 2007). Образующаяся жидкостекольная смесь способна формировать высокопористую систему при относительно низких температурах последующей термообработки.

Для изготовления пеносиликатов использовался кремнеземсодержащий продукт переработки эвдиалитовых руд, состава, мас. \%: $\mathrm{SiO}_{2} 69.90-74.70, \mathrm{TiO}_{2} 0.78-0.84, \mathrm{Al}_{2} \mathrm{O}_{3}$ 0.50-0.91, $\mathrm{Fe}_{2} \mathrm{O}_{3}$ 2.03-3.07, $\mathrm{CaO}$ 0.80-0.91, $\mathrm{MgO} 0.08-0.45, \mathrm{P}_{2} \mathrm{O}_{5}$ 0.04-0.05, $\mathrm{Na}_{2} \mathrm{O}$ 0.32-2.53, $\mathrm{K}_{2} \mathrm{O}$ 0.23-0.46, $\mathrm{ZrO}_{2}$ 4.28-4.49.

Жидкостекольная композиция готовилась с использованием технического гидроксида натрия. Для получения пеносиликатов использовалась шихта состава, мас. \%: кремнеземсодержащий продукт 68-80, гидроксид натрия (в пересчете на $\mathrm{Na}_{2} \mathrm{O}$ ) 17-20, апатито-нефелиновые отходы (Хибинские месторождения) 15, минеральные добавки в количестве 5-30 (сверх 100 \%). В качестве модифицирующих добавок использовались диопсид и вермикулитовые отходы Ковдорского месторождения, доломит (Сопчеозеро), сунгулит (Хабозеро). После перемешивания к компонентам шихты добавляли раствор гидроксида натрия и методом пластического формования готовили образцы в виде цилиндров, которые затем помещали в керамические разъемные формы. Термообработка проводилась в интервале ранее подобранных для данной системы температур от 600 до $750^{\circ} \mathrm{C}$.

Получены пеносиликаты, обладающие мелкопористой структурой с включениями более крупных пор и прочностью до 2 МПа (Суворова О.В. и др., 2019). По своим теплофизическим свойствам они практически полностью соответствуют требованиям для теплоизоляционных материалов. Применение их в качестве конструкционно-теплоизоляционных материалов возможно при улучшении технических характеристик, в т.ч. и путем совершенствования структуры. Для вспученных теплоизоляционных материалов наиболее оптимальной считается структура, которая состоит из полидисперсных по размеру равномерно распределенных пор, разделенных тонкими плотными одинаковыми по сечению межпоровыми перегородками (Углова Т.К. и др., 2010). Наличие такой структуры обеспечивает получение высококачественных материалов.

Одним из способов регулирования свойств пористых материалов является использование исходных компонентов различной крупности. Более крупные частицы создают своеобразный жесткий каркас, который отвечает за сохранность формы материала и за его прочностные характеристики. Тонкодисперсные и жидкие компоненты заполняют образующееся пространство в его массе. Создания наиболее оптимальной структуры можно достичь использованием твердой фазы в виде нескольких порошков с различной крупностью частиц (Углова Т.К., 2010).

Другое направление корректировки свойств жидкостекольной композиции для получения качественного пеносиликатного материала - его модифицирование посредством введения в состав шихты минеральных добавок. Проанализировав многочисленные литературные источники можно сделать предположение, что введение водостойких и прочных добавок, например апатито-нефелиновых 


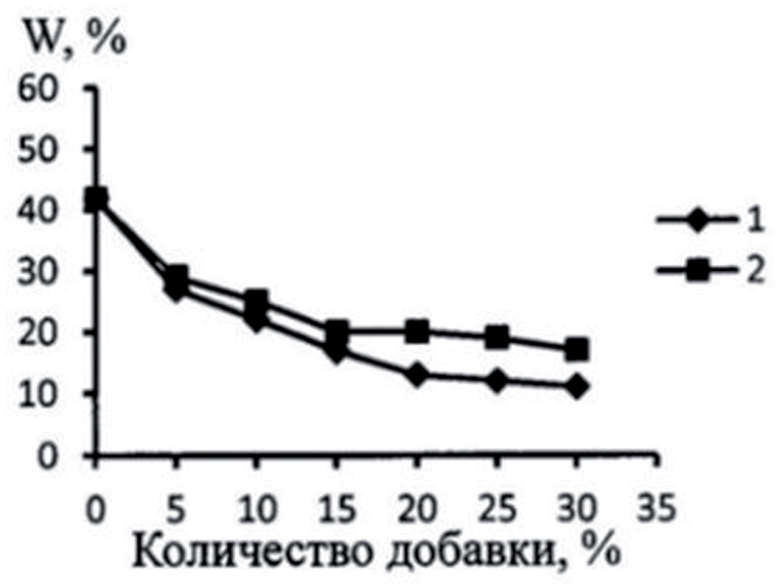

Рис. 2. Зависимость водопоглощения (W) конечного продукта от количества добавок диопсида (1) или хвостов обогащения вермикулитовых руд (2).

Fig. 2. Dependance of water absorption (W) from the diopside amount (1), from refinement tailings of vermiculite ores (2).

отходов и диопсида, улучшает технические свойства готового продукта (Альперович И.А. и др., 1998, Верещагин В.И. и др., 2002, Верещагин В.И. и др., 2010, Манакова, 2017).

Кроме того, как было показано исследованиями, добавление к составу шихты измельченных диопсида и вермикулитовых отходов, способствует снижению показателя водопоглощения и увеличению водостойкости в 2-3 раза, за счет чего необходимость дополнительной обработки материала гидрофобизаторами отпадает (рис. 2).

Обеспечение максимальных прочностных характеристик ячеистой силикатной матрицы возможно при условии целенаправленного формирования ее макро- и микроструктуры.

На рисунке 3 приведены микроструктура и внешний вид полученных плитных вспененных материалов. Варьирование составом шихты и подбор оптимального температурного режима позволяют получать материалы с широким диапазоном свойств.

Поверхность среза образца пеносиликата испещрена порами различной формы, преимущественно округлой и овальной. Наряду с мелкими порами в структуре вспененного материала можно визуально распознать включения более крупных пор. Межпоровые перегородки толщиной 1-50 мкм обладают ячеисто-капиллярной структурой с размером ячеек от 0.1 до 20 мкм. Прочность материалов в значительной мере определяется толщиной и прочностью межпоровых перегородок. От состояния каркаса и стенок пор зависят механические свойства материалов.

Таким образом, проведенные исследования в области получения пеностекольных материалов на основе техногенного сырья Кольского полуострова показали успешное применение отходов обогащения апатито-нефелиновых руд и стеклоотходов для получения пеностеклокристаллического материала порошковым методом.

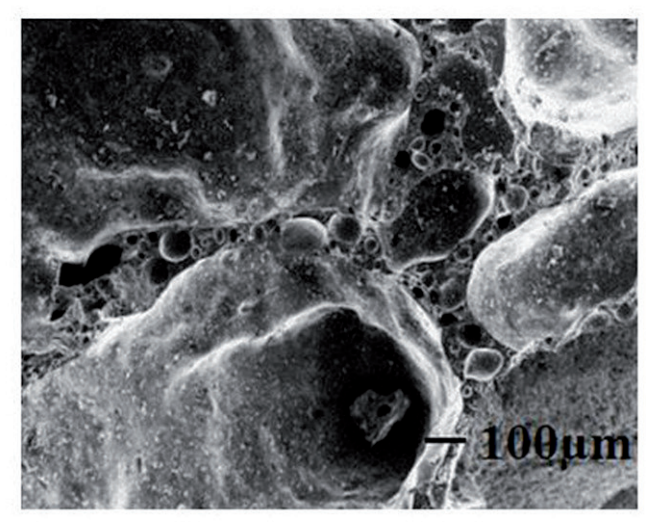

a

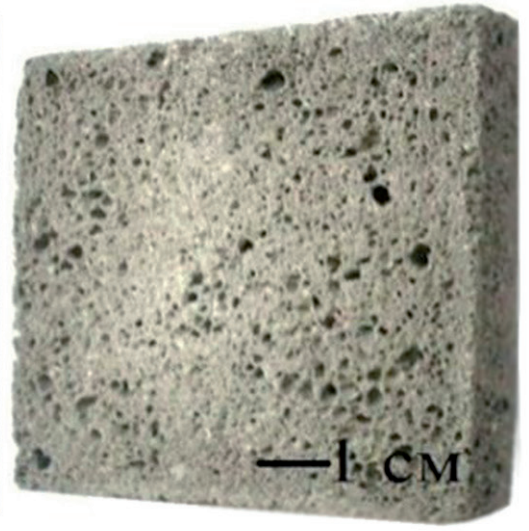

б

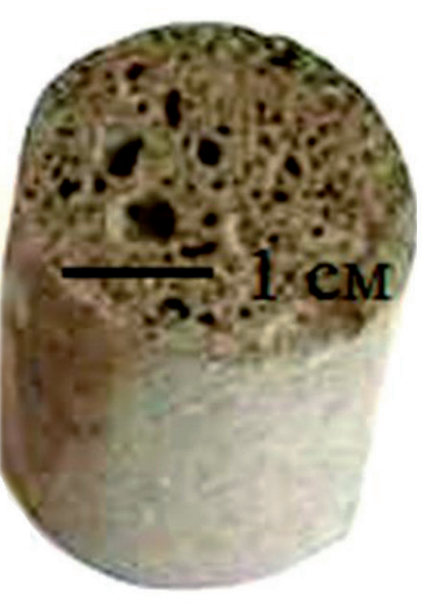

B

Рис. 3. Микроструктура (а) и внешний вид (б, в) пеносиликатов для изготовления теплоизоляционных материалов (температура термообработки $650^{\circ} \mathrm{C}$ ).

Fig. 3. Microstructure (a) and appearance (b, c) of foam silicates for the manufacture of heat-insulating materials (heat treatment temperature $650^{\circ} \mathrm{C}$ ). 
На основе аморфного кремнеземсодержащего продукта переработки эвдиалитовых руд при низких температурах термообработки получены пеносиликаты с относительно равномерной мелко-

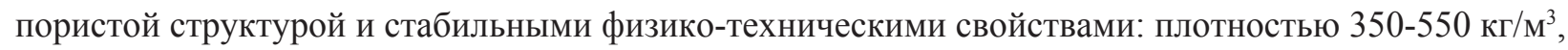
прочностью 1.9-6 МПа, водопоглощением 12-14 \%, теплопроводностью 0.047-0.104 Вт/м·К.

Для расширения сферы применения материалов изучены различные способы улучшения их свойств. Значительное влияние на основные технические характеристики пеносиликатов оказывают оптимизация технологических режимов их получения и использование модифицирующих добавок в составе шихты. Добавки выполняют функцию и модификатора, и наполнителя, способствуя формированию высокопористой структуры.

Экспериментально установлено, что наиболее эффективным по комплексу свойств получаемых материалов является введение в состав шихты добавок доломита в количестве 5-10 \%, сунгулита, диопсида, вермикулитовых отходов в количестве 5-17.5\%.

Разработанные составы и условия синтеза пеносиликатов позволяют создавать материалы с заданными физико-техническими свойствами для применения в различных областях строительной отрасли.

Работа выполнена в рамках темы НИР №0226-2019-0068 и частично поддержана из средств гранта РФФИ (17-43-510364).

\section{Литература}

1. Альперович И.А. Керамические стеновые и теплоизоляционные материалы в современном строительстве // Строительные материалы. 1998. № 2. С. 22-23.

2. Верещагин В.И., Борило Л.П., Козик А.В. Пористые композиционные материалы на основе жидкого стекла и природных силикатов // Стекло и керамика. 2002. № 9. С. 26-28.

3. Верещагин В.И., Меньшикова В.К., Бурученко А.Е., Могилевская Н.В. Керамические материалы на основе диопсида // Стекло и керамика. 2010. № 11. С. 13-16.

4. Казанцева Л.К., Сереткин Ю.В., Железнов Д.В., Ращенко С.В. Формирование источника порообразующего газа при увлажнении природных алюмосиликатов раствором $\mathrm{NaOH} / /$ Стекло и керамика. 2012. № 10. C. 37-42.

5. Кетов А.А., Пузанов И.С., Саулин Д.В. Тенденции развития технологии пеностекла // Строительные материалы. 2007. № 9. С. 28-31.

6. Кетов А.А., Толмачев А.В. Пеностекло - технологические реалии и рынок // Строительные материалы. 2015. № 1. С. 17-31.

7. Кудяков А.И., Радина Т.Н., Свергунова Н.А. Технология получения легкого материала на основе микрокремнезема // Строительные материалы. 2002. № 10. С. 34.

8. Манакова Н.К., Суворова О.В. Горнопромышленные отходы мурманской области для получения блочных пеносиликатов // Труды Ферсмановской Научной Сессии ГИ КНЦ РАН. 2017. № 14. С. 243-245.

9. Манакова Н.К., Суворова О.В. Снижение нагрузки на окружающую среду за счет вовлечения техногенных отходов в получение теплоизоляционных материалов // Труды Ферсмановской научной сессии ГИ КНЦ РАН. 2019. № 16. С. 360-363. (DOI:10.31241/FNS.2019.16.072).

10. Суворова О.В., Макаров Д.В. Пеностекла и пеноматериалы на основе золошлаковых отходов теплоэлектростанций // Стекло и керамика. 2019. № 5. С. 33-39.

11. Суворова О.В., Манакова Н.К. Влияние технологических режимов на свойства и структуру пеносиликатов // Труды Кольского научного центра РАН. Химия и материаловедение. Вып. 2. Исследования и разработки в области химии и технологии функциональных материалов. Сборник трудов III-ой Всероссийской научной конференции с международным участием, посвященной 60-летию ИХТРЭМС ФИЦ КНЦ РАН, Апатиты. 2018. 2. С. 894-897. DOI: 10.25702/KSC. 2307-5252.2018.9.1.894-89.

12. Терещенко И.М., Дормешкин О.Б., Кравчук А.П., Жих Б.П. Состояние и перспективы развития производства стекловидных вспененных теплоизоляционных материалов // Стекло и керамика. 2017. № 6. С. 29-32.

13. Тихомирова И.Н., Скорина Т.В. Теплоизоляционные материалы на основе кремнеземсодержащего сырья // Строительные материалы. 2008. № 10. С. 58-60.

14. Углова Т.К., Новоселова С.Н., Татаринцева О.С. Экологически чистые теплоизоляционные материалы на основе жидкого стекла // Строительные материалы. 2010. № 10. С. 44-46.

15. Пат. РФ №2246457 МПК С 03 С 11/00. Шихта для получения пеностекольного облицовочного материала / Калинников В.Т., Макаров В.Н., Суворова О.В., Макаров Д.В., Кулькова Н.М. Ин-т химии и 
технол. редких элем. и минер. сырья Кол. науч. центра РАН. - № 2003118339. Заявл. 17.06.03. Опубл. 20.02.05. Бюл. №5.

16. Пат. РФ № 2267468 МПК С1 С 04 В 28/26 С 04 В18/14 С 04 В 24/08 С 04 В 111/20. Сырьевая смесь и способ получения гранулированного теплоизоляционного материала / Кудяков А.И., Радина Т.Н., Иванов М.Ю.; Братский государственный технический университет. - N 2004109731/03; Заявл. 30.03.2004; Опубл. 10.01.2006. Бюл. №23.

17. Пат. РФ №2300506, МПК С 04 В 28/24 С04 В 111/20 С 04 В 111/40 (2006.01). Строительный материал и способ его получения / Н.А. Меркин, Б.В. Писарев, А.Б. Фащевский. №- 2006117011/03; Заявл. 17.05.2006; Опубл. 10.06. 2007. Бюл. №16.

18. Лащук В.В., Мельник Н.А., Нестеров Д.П., Нестерова А.А., Усачева Т.Т. Комплексная характеристика хранилищ, содержащих отходы обогащения апатит-нефелиновых руд хибинских месторождений // Труды Ферсмановской научной сессии ГИ КНЦ РАН. 2007. №4. С. 305-308. 